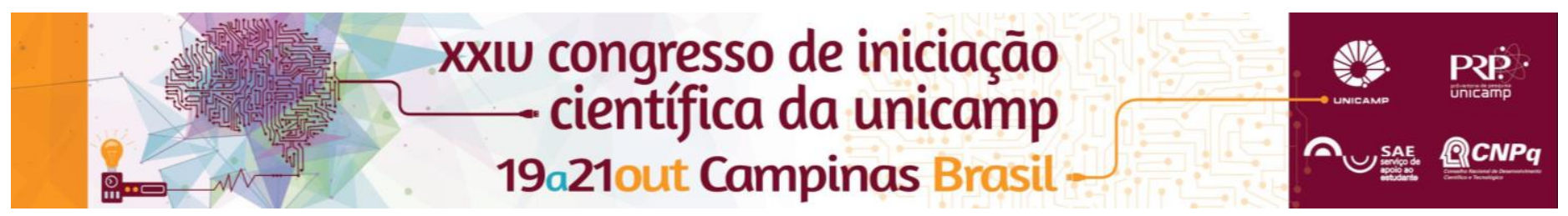

\title{
Preparação e caracterização de biocompósitos híbridos baseados em nanocristais de celulose e fibras de munguba.
}

\section{Guilherme F. Alves*, Ivanei F. Pinheiro, Lucia H. Innocentini Mei}

\section{Resumo}

Neste trabalho incorporou-se nanocristais de celulose e fibras de Munguba (Pseudobombax mumguba) na matriz polimérica Poli(butileno adipato-co-tereftalato)-PBAT e avaliou-se as propriedades dos nanocompósitos híbridos. Foram preparados nanocristais a partir de uma reação de hidrólise ácida com solução de ácido súlfurico a $55 \%$ v/v, com sua posterior modificação, para melhorar sua interação com a matriz polimérica. A caracterização da modificação química foi feita por Espectroscopia no Infravermelho(FT-IR), e a avaliação da interação química e mudanças na polaridade por ângulo de contato. Após o processamento dos compósitos em um Reômetro de torque e a obtenção dos corpos de prova, fez-se a caracterização das propriedades físicas dos biocompósitos por Ensaios Mecânicos de Tração (ASTM D 638-10); verificação da estabilidade termica por Análise Termogravimétrica (TGA); determinação da temperatura de fusão $(\mathrm{Tm})$,de cristalização e de transição vítrea $(\mathrm{Tg})$ do material híbrido por Calorimetria Exploratória Diferencial (DSC) e a morfologia dos nanocristais com o auxílio de um Microscópio Eletrônico de Transmissão - MET.

\section{Palavras-chave:}

Fibras Naturais, Nanocristal de Celulose, Polímeros Biodegradáveis.

\section{Introdução}

Materiais ambientalmente corretos vêm sendo produzidos para diminuir os impactos ambientais. Seguindo esta linha, a produção de nanocompósitos com fibras naturais começou a crescer. O fato de ser matéria prima natural, biodegradável, renovável, atóxica e geralmente com baixo custo, além de ocasionar menor desgaste em equipamentos, quando comparado com fibras sintéticas, faz da fibra natural um grande atrativo como reforço para matrizes poliméricas. Além da facilidade em que são modificadas por agentes químicos, suas propriedades são semelhantes às fibras sintéticas. Atualmente além da fibra, há a utilização de dois ou mais reforços em uma única matriz, formando um compósito híbrido. Com a aplicação desses reforços há uma melhora nas propriedades da matriz para uma determinada aplicação. $O$ trabalho visa estudar compósitos híbridos utilizando poli (butileno adipato-cotereftalato) - PBAT como matriz e nanocristais de celulose/fibras de Munguba como reforço.

\section{Resultados e Discussão}

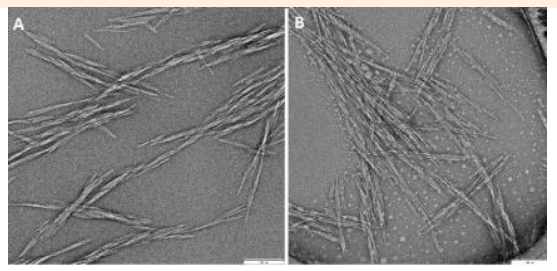

Figura 1. Morfologia dos nanocristais de celulose microcristalina (a) e de fibra de munguba (b).

Ambos os nanocristais apresentaram as condições necessárias para agirem como reforço. Constatou-se pela análise de ângulo de contato que após a modificação química, estes passaram de um caráter hidrofílico para hidrofóbico.

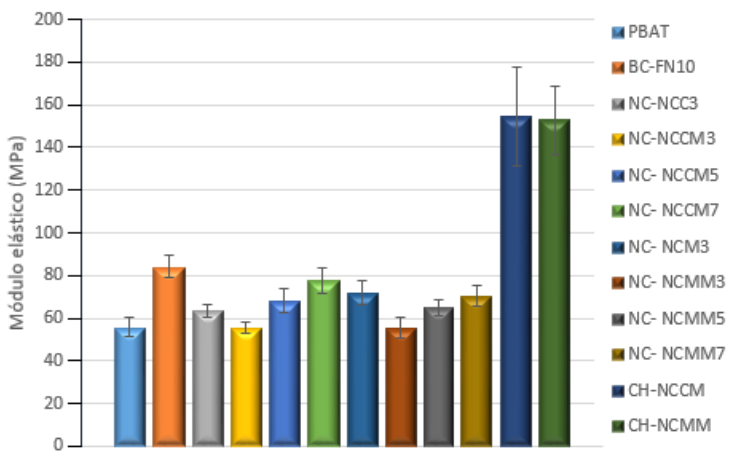

Figura 2. Módulos elásticos das amostras obtidos por ensaios mecânicos de tração.

Amostras a partir de $5 \%$ de carga obtiveram efeito significativo no módulo de elasticidade, em comparação com a matriz pura. A combinação nanocristal e fibra gerou um aumento significativo na rigidez do material. Verificou-se um aumento na tensão de ruptura após a modificação química. Pela análise termogravimétrica observou-se que a modificação química do nanocristal não influenciou na estabilidade térmica do PBAT. A análise por Calorimetria Exploratória Diferencial indicou que a adição de cargas proporciona um processo de nucleação heterogênea na matriz, aumentando a temperatura de cristalização da mesma e diminuindo sua temperatura de transição vítrea $(\mathrm{Tg})$.

\section{Conclusões}

A modificação química de nanocristais mostrou-se eficaz, e permite que os nanocristais sejam aplicados tanto em matrizes hidrofílicas quanto hidrofóbicas, devido a mudança de sua polaridade. A adição de nanocristais de celulose ou fibras de Munguba, não proporcionou melhorias na estabilidade térmica da matriz, e acarretou um aumento na elasticidade do PBAT.

HASSAN et al. Polycaprolactone/Modified Bagasse Whisker Nanocomposites with Improved Moisture-Barrier and Biodegradability Properties. Journal of Applied Polymer Science, v. 125, p. e10-e19, 2012. 